\title{
Stress Analysis of Crankshaft Subjected To Dynamic Loading
}

\author{
T. Anbu ${ }^{1}$, S. Govindaraji ${ }^{2}$, C. Kannadhasan ${ }^{3}$, S. Selvakumar ${ }^{4}$ \\ 1,2,3,4 (Engineering design, Priyadarshini Engineering College/, India)
}

\begin{abstract}
In this study a dynamic simulation was conducted on crankshaft, from multi cylinder four stroke engines. Finite element analysis was performed to obtain the variation of stress magnitude. The load diagram was used to calculate the load boundary condition. This load was then applied to the FE model and boundary conditions were applied according to the engine mounting conditions. From this analysis a model of crankshaft is generated in PRO -E, meshes by the HYPER MESH and analyzed in ANSYS using FEM (finite element method) by applying loads and boundary conditions, and then solved for engineering responses and Stress variation over the engine cycle. The scope of the FE Analysis of the crank shaft under static, modal and transient analysis was carried out to predict the stresses and its deformations.
\end{abstract}

Keywords: Dynamic Simulation, Crank Shaft Under Static.

\section{Introduction}

Crankshaft is a large component with a complex geometry in the engine, which converts the reciprocating displacement of the piston to a rotary motion with a four link mechanism. Since the crankshaft experiences a large number of load cycles during its service life, fatigue performance and durability of this component has to be considered in the design process. Design developments have always been an important issue in the crankshaft production industry, in order to manufacture a less expensive component with the minimum weight possible and proper fatigue strength and other functional requirements.

\section{Design Procedure}

The following procedure may be adopted for a crankshaft. find the magnitude of the various loads on the crankshaft. Determine the distances between the supports and their position with respect to the loads. For the sake of simplicity and also for safety, the shaft is considered to be supported at the centre of the bearings and all the forces and reactions to be acting at these points. The distances between the supports depend on the length of the bearings, which in turn depend on the diameter of the shaft because of the allowable bearing pressures. The thickness of the cheeks or webs is assumed to be from $0.4 \mathrm{ds}$ to $0.6 \mathrm{ds}$, where ds are the diameter of the shaft. It may also be taken as $0.22 \mathrm{D}$ to $0.32 \mathrm{D}$ where $\mathrm{D}$ is the bore diameter of cylinder in $\mathrm{mm}$. Now calculate the distances between the supports. Assuming the allowable bending and shear stresses, determine the main dimensions of the crankshaft.

\section{Indentations and Equations}

Design of the crankshaft when the crank is at the dead centre

Bore diameter $\mathrm{D}=160 \mathrm{~mm}$

Stroke $\mathrm{L}=120 \mathrm{~mm}$

Mean effective Pressure $\mathrm{pm}=0.5 \mathrm{~N} / \mathrm{mm} 2$

Combustion pressure $\mathrm{p}=2 \mathrm{~N} / \mathrm{mm} 2$

Flywheel weight $\mathrm{W}=50 \mathrm{KN}$

Total belt pull $(\mathrm{T} 1+\mathrm{T} 2)=17.51 \mathrm{KN}$ Pressure on piston $\mathrm{p}{ }^{c}=1 \mathrm{~N} / \mathrm{mm} 2$

Crank angle $\theta=35^{\circ}$ We know that the piston gas load,

$\mathrm{Fp}=(Л / 4) \times \mathrm{D} 2 \times \mathrm{p}(3.1)=(Л / 4) \times(160) 2 \times 2=40.21 \mathrm{KN}$

Assume that the distance (b) between the bearings $1 \& 2$ is equal to the piston diameter (D).

$\mathrm{b}=2 \times(200+200)=800 \mathrm{~mm}$

And $\mathrm{b} 1=\mathrm{b} 2=(\mathrm{b} / 2)(3.2)=(800 / 2)=400 \mathrm{~mm}$

We know that due to the piston gas load, there will be two horizontal reactions H1 \& H2 at bearings

$1 \& 2$ respectively,

such that $\mathrm{H} 1=\{(\mathrm{Fp} \mathrm{x} \mathrm{b1}) / \mathrm{b}\}(3.3)=\{(40.21 \times 400) / 800\}=20.1 \mathrm{KN}$

And $\mathrm{H} 2=\{(\mathrm{Fp} \mathrm{x} \mathrm{b2}) / \mathrm{b}\}(3.4)=\{(40.21 \times 400) / 800\}=20.1 \mathrm{KN}$

Assume that the length of the main bearings to be equal, i.e. $\mathrm{c} 1=\mathrm{c} 2=\mathrm{c} / 2$.

We know that due to the weight of the flywheel acting downwards, there will be two vertical reactions V2 \& V3 at bearing $2 \& 3$ respectively, such that $\mathrm{V} 2=\{(\mathrm{W} \mathrm{x} \mathrm{c1}) / \mathrm{c}\}=\{[\mathrm{W} \mathrm{x}(\mathrm{c} / 2)] / \mathrm{c}\}(3.5)=\mathrm{W} / 2=50 / 2=25 \mathrm{KN}$

And $\mathrm{V} 3=\{(\mathrm{W} \times \mathrm{c} 2) / \mathrm{c}\}=\{[\mathrm{W} \times(\mathrm{c} / 2)] / \mathrm{c}\}(3.6)=\mathrm{W} / 2=50 / 2=25 \mathrm{KN}$ 
Due to the resultant belt tension $(\mathrm{T} 1+\mathrm{T} 2)$ acting horizontally, there will be horizontal reactions $\mathrm{H} 2^{`}$ \& $\mathrm{H} 3^{\text {‘ }}$ respectively, such that

$\mathrm{H} 2^{\circ}=\{[(\mathrm{T} 1+\mathrm{T} 2) \mathrm{c} 1] / \mathrm{c}\}(3.7)=(\mathrm{T} 1+\mathrm{T} 2) / 2(3.8)=17.51 / 2=8.755 \mathrm{KN}[\mathrm{c} 1=(\mathrm{c} / 2)]$

$\mathrm{H}^{\circ}=\{[(\mathrm{T} 1+\mathrm{T} 2) \mathrm{c} 2] / \mathrm{c}\}(3.9)=(\mathrm{T} 1+\mathrm{T} 2) / 2=17.51 / 2=8.755 \mathrm{KN}[\mathrm{c} 2=(\mathrm{c} / 2)]$

\section{Design Of Crankpin}

Let $\mathrm{dc}=$ Diameter of the crankpin in $\mathrm{mm}, \mathrm{lc}=$ Length of the crankpin in $\mathrm{mm}, \sigma \mathrm{b}=$ Allowable bending stress for the crankpin in $\mathrm{N} / \mathrm{mm} 2$. For Plain carbon steel $\sigma \mathrm{b}=(480 / 5)=96 \mathrm{~N} / \mathrm{mm} 2$ [From the PSGDB Page.No:1.8] We know that bending moment at the centre of the crankpin, $\mathrm{Mc}=\mathrm{H} 1 \mathrm{x}$ b2 (3.10) $=20.1 \times 400=8040 \mathrm{KN}-\mathrm{mm}$ We also know that $\mathrm{Mc}=(Л / 32) \times(\mathrm{dc}) 3 \times$ ob $(3.11)=(Л / 32) \times(\mathrm{dc}) 3 \times 96=9.424(\mathrm{dc}) 3 \mathrm{~N}-\mathrm{mm}$ $\mathrm{Mc}=9.424 \times 10-3(\mathrm{dc}) 3 \mathrm{KN}-\mathrm{m}(\mathrm{dc}) 3=3946 / 9.424 \times 10-3=94.85 \mathrm{~mm} \mathrm{dc}=94.85 \approx 100 \mathrm{~mm}$ We know that length of the crankpin IC $=\mathrm{Fp} / \mathrm{dc} \times \mathrm{pb}=40.21 \approx 40 \mathrm{~mm}$ Where [Taking Permissible bearing pressure $\mathrm{pb}=10 \mathrm{~N} / \mathrm{mm} 2]$

\section{Design Of Left Hand Web}

We know that thickness of the crank web, $\mathrm{t}=0.65 \mathrm{dc}+6.35 \mathrm{~mm}(3.12) \mathrm{t}=(0.65 \times 100)+6.35=71.3 \approx$ $75 \mathbf{~ m m}$ And width of the web, $\mathrm{w}=1.125 \mathrm{dc}+12.7 \mathrm{~mm}(3.13) \mathrm{w}=(1.125 \times 100)+12.7=125.2 \approx \mathbf{1 3 0} \mathbf{~ m m}$ We know that maximum bending moment on the crank web, $\mathrm{M}=\mathrm{H} 1 \mathrm{~b} 2(\mathrm{lc} / 2)(\mathrm{t} / 2)(3.14)$

$=9.815 \times 400(40 / 2)(75 / 2)$

$=6984.75 \mathrm{KN}-\mathrm{mm}$

Bending stress $(\sigma \mathrm{b}), \sigma \mathrm{b}=59.60 \mathrm{~N} / \mathrm{mm} 2$

And direct compressive stress on the crank web, $\sigma c=2.06 \mathrm{~N} / \mathrm{mm} 2$

Total stress on the crank web $=$ Bending stress + direct compressive stress $=\sigma b+\sigma c=59.6+2.06=61.66$ $\mathrm{N} / \mathrm{mm} 2$ (or) MPa Since the total stress on the crank web is less than the allowable bending stress of $96 \mathrm{MPa}$, therefore, the design of the left hand crank web is safe.

\section{Design Of Web Right Hand Crank}

From the balancing point of view, the dimensions of the right hand crank web (i.e. thickness and width) are made equal to left hand web.

\section{Design Of Shaft Under The Fly Wheel}

Let $\mathrm{ds}=$ Diameter of the shaft in $\mathrm{mm}$, Since the lengths of the main bearings are equal, therefore $11=12=13=$ $2[(\mathrm{~b} / 2)-(\mathrm{lc} / 2)-\mathrm{t}](3.16)=2[400-15-60]=650 \mathrm{~mm}$

Allowing space for gearing and clearance, let us take $\mathrm{c}=800 \mathrm{~mm} . \mathrm{c} 1=\mathrm{c} 2=(\mathrm{c} / 2)=(800 / 2)=400 \mathrm{~mm}$

We know that bending moment due to the weight of flywheel, MW=V3 $. \mathrm{c} 1(3.17)=25$ x $400=10,000 \mathrm{KN}-\mathrm{mm}$ $=10 \times 106 \mathrm{~N}-\mathrm{mm}$

And bending moment due to belt tension,

$\mathrm{MT}=\mathrm{H}^{`} . \mathrm{c} 1=8.755 \times 400=3502 \mathrm{KN}-\mathrm{mm}=3.5 \times 106 \mathrm{~N}-\mathrm{mm}$

Therefore, the resultant bending moment on the shaft,

$\mathrm{MS}=(\mathrm{MW}) 2+(\mathrm{MT}) 21 / 2=(10 \times 106) 2+(3.5 \times 106) 21 / 2 \mathrm{MS}=10.56 \times 106 \mathrm{~N}-\mathrm{mm}$ We also know that the bending moment on the shaft,

$10.56 \times 106=($ Л/32) $\times(\mathrm{ds}) 3 \mathrm{x} \sigma \mathrm{b}=($ Л/32) $\mathrm{x}(\mathrm{ds}) 3 \times 96 \mathrm{ds}=103.96 \mathrm{~mm} \approx \mathbf{1 1 0} \mathbf{~ m m}$

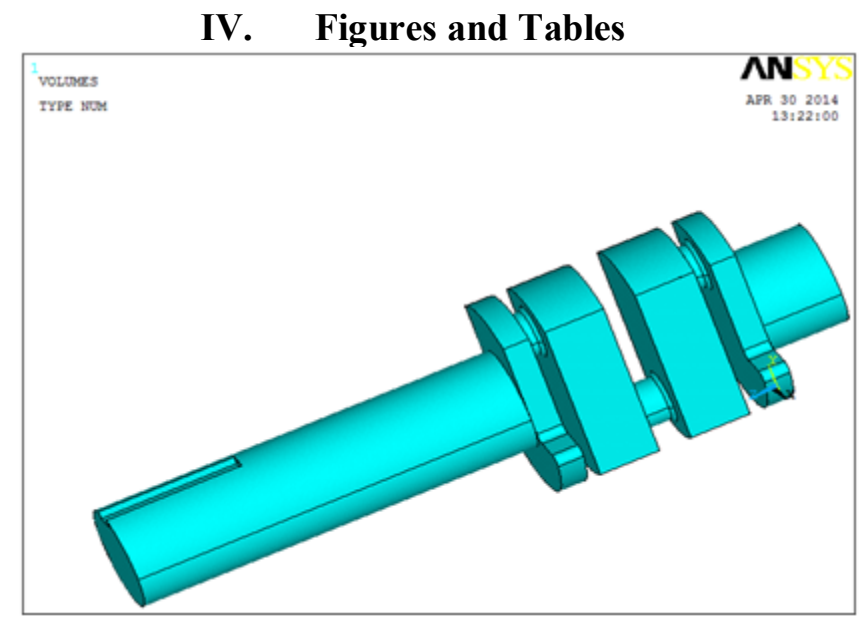

Fig: 1 Ansys Drawing Of Modified Crank Shaft 


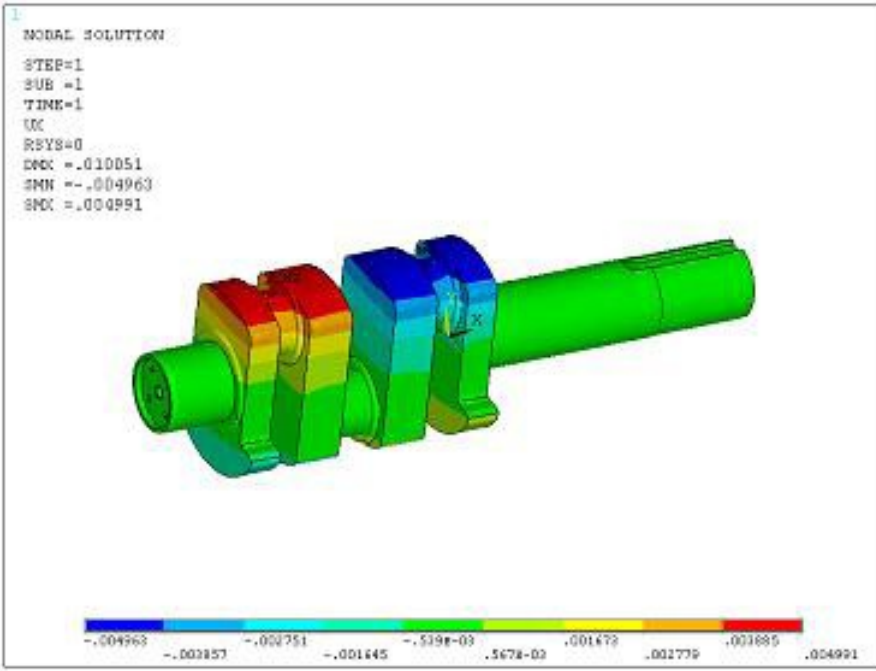

Fig: 2 Displacements In X Direction
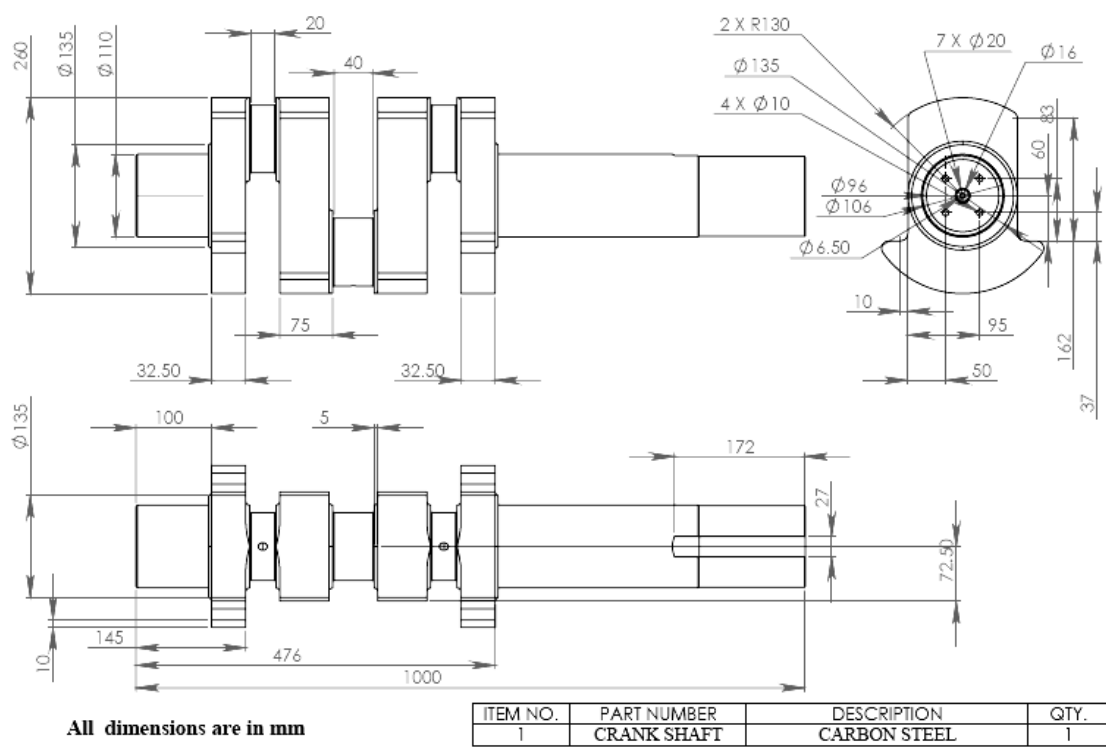

Fig: 3 Detail Drawing Of Crank Shaft

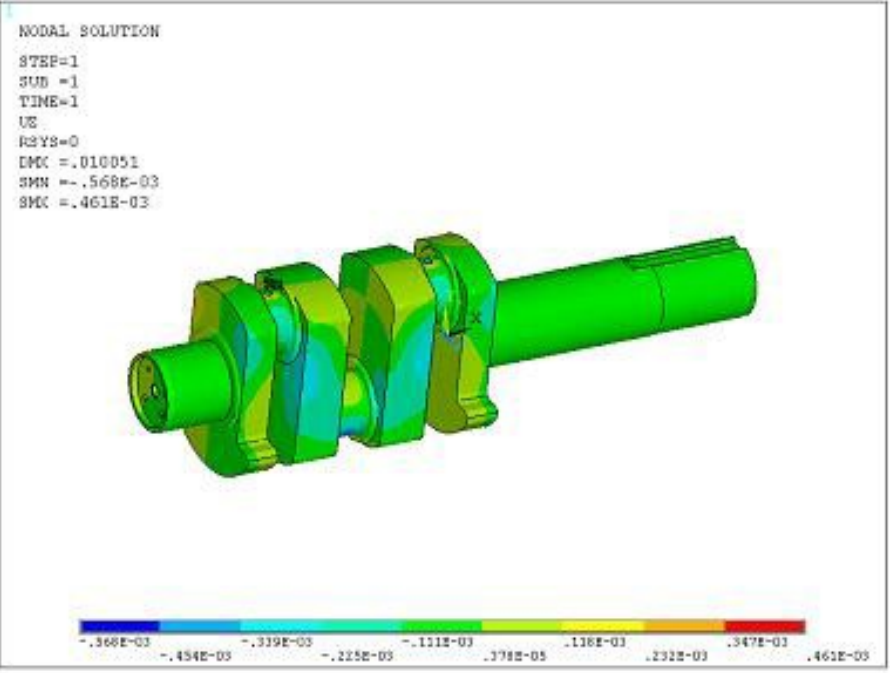

Fig: 4 Displacements In Y Direction 


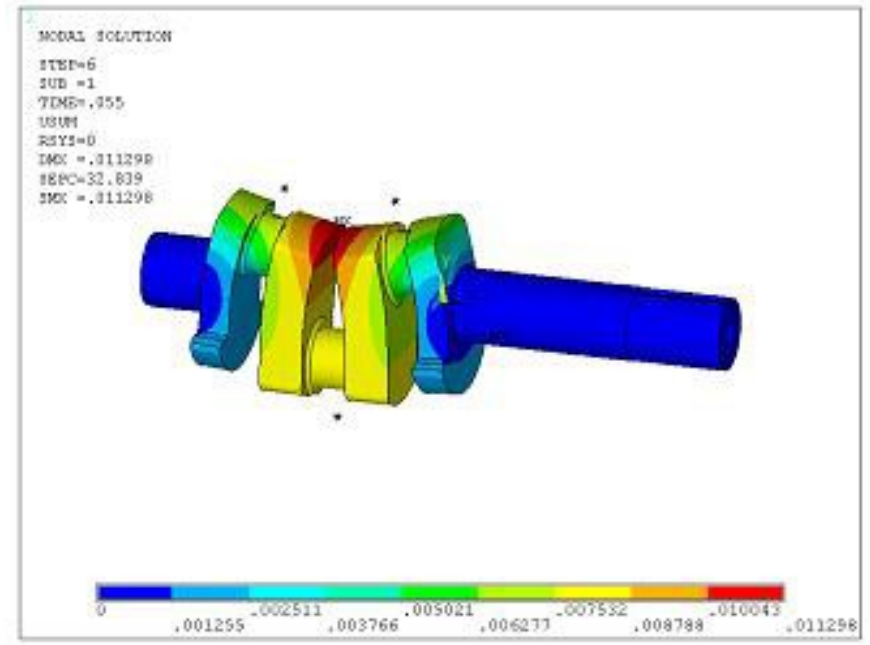

Fig: 5 Equivalent Displacement Diagram

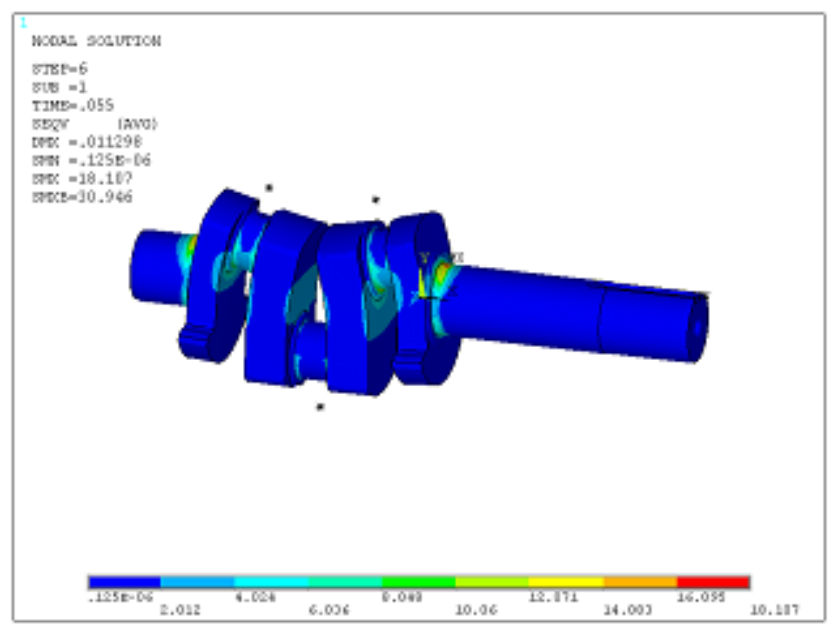

Fig: 6 Equivalent Stress Displacement Diagram

\begin{tabular}{|c|c|c|c|c|c|}
\hline SI .No & Mechanical Terms & Theoretical Value & Static Analysis & Modal Analysis & Transient Analysis \\
\hline 1 & Shaft Diameter In Mm & 110 & 110 & 110 & 110 \\
\hline 2 & Shear Stress In Mpa & 43.23 & - & - & 30.7 \\
\hline
\end{tabular}

\section{Table: 1 Value Of Analysis}

\section{Conclusion}

Thus the Crankshaft is designed based on the shaft whose diameter $110 \mathbf{~ m m}$.

1. There are two different load sources in an engine; inertia and combustion. These two load source cause both bending and torsional load on the crankshaft. Considering torsional load in the overall dynamic loading conditions has no effect on von misses stress at the critically stressed location (in fillet areas). The effect of torsion on the stress range is also relatively small at other locations undergoing torsional load. Therefore, the crankshaft analysis could be simplified to applying only bending load.

2. Geometry optimization resulted in $18 \%$ weight reduction of the forged steel crankshaft, which was achieved by changing the dimensions and geometry of the crank webs while maintaining dynamic balance of the crankshaft. This stage of optimization did not require any changes in the engine block or connecting rod. 3. Adding fillet rolling was considered in the manufacturing process. Fillet rolling induces compressive residual stress in the fillet areas, which results in $165 \%$ increase in fatigue strength of the crankshaft and increases the life of the component significantly.

4. Using micro alloyed steel as an alternative material to the current forged steel results in the elimination of the heat treatment process. In addition, considering better mach inability of the micro alloyed steel along with the reduced material cost due to the $18 \%$. 


\section{References}

[1]. Website: www.wikipedia.com

[2]. Nakada, T. and Tonosaki, T. Excitation mechanism of half order engine vibrations. International Conference on Vehicle NVH \&Refinement, Paper C487/017/94 IMechE, MEP Press, 1994, pp.1-7

[3]. Kirk, R. G. and Gunter, E. J. Short bearings analysis applied torotor dynamics, Part 2: Results of journal bearing response

[4]. chrisbaker. A dynamic review on condition monitoring and fault diagnosis for diesel engines. Condition monitoring'97. Xi'an, CSICE 1995.

[5]. A Text book of Machine Design Eurasia Publishing House (Pvt) Ltd, 2010 - R.S. Khurmi \& J.K. Gupta

[6]. PSG Design Datall, Kalaikathir Achchagam, 2003

[7]. Norton L.R Machine Design - An integrated Approach Pearson Education,2005

[8]. Shigley, J.E Mechanical Engineering Design Mcgraw Hill 1985

[9]. BOltzharol A Material Handling Hand book, The Ronald Press Company 1958 